HIV

\title{
Diagnoses of HIV-1 and HIV-2 in England, Wales, and Northern Ireland associated with west Africa
}

\author{
S Dougan, B Patel, J H Tosswill, K Sinka
}

See end of article for authors' affiliations

.....................

Correspondence to: $S$ Dougan, Department of HIV and Sexually

Transmitted Infections, Communicable Disease Surveillance Centre, Health Protection Agency Centre for Infections, 61 Colindale Avenue, London NW9 5EQ, UK; sarah.dougan@ hpa.org.uk

Accepted for publication 26 October 2004
Sex Transm Infect 2005;81:338-341. doi: 10.1136/sti.2004.013011
$\mathrm{T}$ he number of HIV infections acquired in west Africa and diagnosed in England, Wales, and Northern Ireland (E,W\&NI) has risen in recent years. ${ }^{1}$ In west Africa, adult HIV prevalence ranges from less than $1 \%$ in Mauritania to $7 \%$ in Ivory Coast. ${ }^{2}$ In this region, the epidemic is diverse and changeable with overall figures often concealing very high infection levels among certain population groups. ${ }^{2}$ An estimated 35000 people migrated from west Africa to the United Kingdom between 1998 and 2002, ${ }^{3}$ and an increasing number of UK nationals travel to the region each year. An estimated 130000 visits were made in 2002, nearly half to visit friends and family. ${ }^{4}$

To date, the majority of HIV-2 infections diagnosed in E,W\&NI have been acquired in west Africa. ${ }^{5}$ HIV-2 infection is endemic in west Africa, with further spread to countries with strong links to the region. While HIV-2 is less pathogenic than HIV-1, with prolonged periods of asymptomatic infection, ${ }^{6}$ the diagnosis of HIV-2 infection has implications for choice of antiretroviral therapy ${ }^{7}$; the clinical management of pregnant women to prevent mother to child transmission ${ }^{10}$; the diagnosis and monitoring of HIV infection in children born to HIV infected pregnant women; and the quantification of HIV-2 RNA, as no commercial assays are currently available. ${ }^{9}$

We describe diagnoses, including those of HIV-2 infection, made in E,W\&NI among those probably infected in west Africa, and consider whether there is evidence for ongoing heterosexual transmission within the United Kingdom.

\section{METHODS}

The Communicable Disease Surveillance Centre (CDSC) receives voluntary and confidential reports of HIV diagnoses in adults $(15+$ years) in E,W\&NI from laboratories (since 1985) and clinicians (since 2000). ${ }^{11}$ Probable route of infection (for example, sex between men, injecting drug use) is collected for all reports and followed up where missing. Probable country of infection is collected for all reports but is only followed up for those infected through heterosexual intercourse. The question takes the format: "Patient presumed infected in the United Kingdom? [Y/N/ NK]. If no, in which country(ies)?" If an individual is presumed infected through sex between men and women within the United Kingdom, then the partner's probable route and country of infection are also recorded. Where more than one possible country of infection is given, the country with highest HIV prevalence is allocated. Here, west Africa is taken to include Benin, Burkina Faso, Cape Verde, Gambia, Ghana, Guinea, Guinea-Bissau, Ivory Coast, Liberia, Mali, Mauritania, Niger, Nigeria, Senegal, Sierra Leone, St Helena, and Togo, as defined by the United Nations.

HIV type (HIV-1, HIV-2, or HIV-1/HIV-2 co-infection) is collected for all reports of HIV diagnoses made to CDSC, and followed up if reported as HIV-2 or HIV-1/HIV-2 co-infection for verification. In UK laboratories, HIV-l infection is assumed if one of three reactive screening assays incorporating only HIV-l antigen is used and reactivity is not unexpectedly low. In the case of a weak or negative reaction in the HIV-1 specific assay, either HIV-2 infection or recent HIV-l seroconversion are considered..$^{12}$ A "line assay," such as Liatek/Innolia, or a rapid test device, which incorporates type specific reaction spots, are often employed to discriminate between HIV-1 and HIV-2 infection. ${ }^{12}$ Suspected

Abbreviations: CDSC, Communicable Disease Surveillance Centre; E,W\&NI, England, Wales, and Northern Ireland; IQR, interquartile range; NNRTls, non-nucleoside reverse transcriptase inhibitors; SOPHID, Survey of Prevalent HIV Infections Diagnosed; UAPMP, Unlinked Anonymous Prevalence Monitoring Programme 
anti-HIV-2 positive, dually reactive specimens, and other specimens with anomalous results are referred to a reference laboratory where they are tested by a variety of additional discriminatory methods that may include a native antigen based western blot. ${ }^{12}$

Median ages and interquartile ranges (IQR) were calculated using Epi-Info 6 (v.6.04d). Data were analysed to the end of 2003, based on reports received by the end of March 2004. Figures for 2003 are expected to rise as further reports are received and follow up continues.

Data from other national surveillance systems, notably the Survey of Prevalent HIV Infections Diagnosed (SOPHID) and the Unlinked Anonymous Prevalence Monitoring Programme (UAPMP) are not included, as infections associated with west Africa cannot be differentiated.
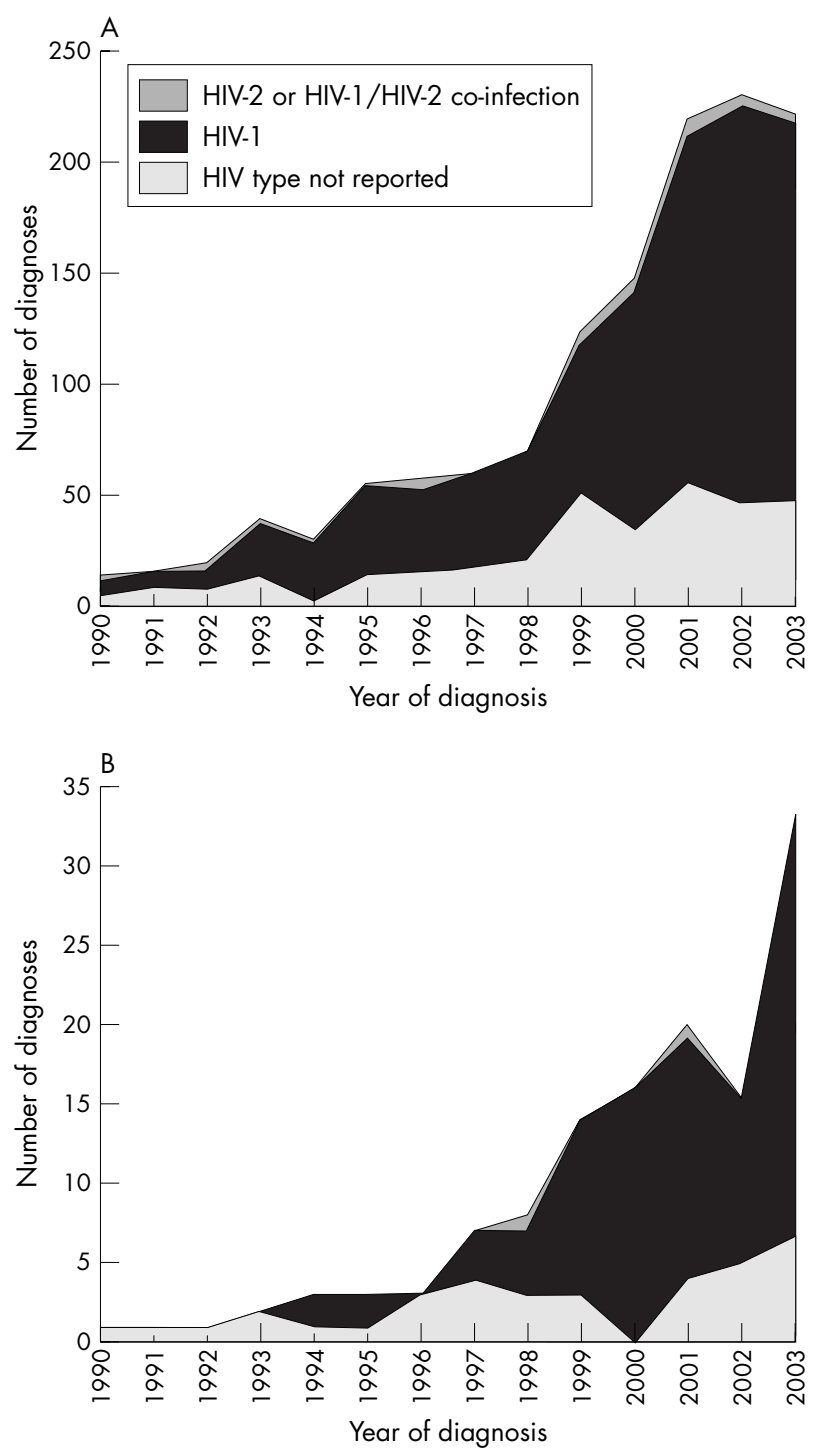

Figure 1 Number of HIV diagnoses made in England, Wales, and Northern Ireland among adults probably infected in west Africa or among adults probably infected through heterosexual intercourse in the United Kingdom by a heterosexual partner probably infected in west Africa: 1985 to 2003. (A) Probably infected in west Africa. (B) Probably infected through heterosexual intercourse within the United Kingdom by a heterosexual partner infected in west Africa. Note: numbers for 2003 are expected to rise as further reports are received and follow up continues.

\section{RESULTS}

Between 1985 and 2003 inclusive, 1324 individuals diagnosed and reported with HIV in E,W\&NI had probably been infected in west Africa. Numbers of diagnoses have risen over time, with 222 diagnoses in 2003 (fig lA). Cumulatively, a further 130 individuals were probably infected through heterosexual intercourse within the United Kingdom by a partner who was heterosexually infected in west Africa. Numbers of such diagnoses have risen in recent years, with 33 in 2003 (fig 1B).

\section{Probably infected in west Africa}

Of the 1324 adults diagnosed in E,W\&NI who were probably infected in west Africa, 917 (69\%) were HIV-1-infected and $52(6 \%)$ were HIV-2 or HIV-1/HIV-2 co-infected. For 355 (27\%) the HIV type was not reported. The number of HIV-2 infections and HIV-1/HIV-2 co-infections diagnosed over time remained relatively constant (fig 1A).

Of the total probably infected in west Africa (1324), 728 (55\%) were women and 596 were men, with median ages at diagnosis of 30 years (IQR 26-35 years) and 36 years (IQR 30-43 years), respectively. In all, 223 women (31\%) were pregnant at diagnosis (six were HIV-2 positive). Where reported (1147), 1057 (92\%) were black African, 64 (6\%) were white, and the remainder other ethnicities. Country of birth was reported for $613(46 \%)$ individuals: 428 (70\%) were born in west Africa, 144 (23\%) in other African regions, 34 in the United Kingdom, and the remainder elsewhere. Of the total (1324), 1050 (79\%) were diagnosed in London.

Of the 1324 infections, 1269 (96\%) were probably infected through heterosexual intercourse, 29 through sex between men, 16 through blood transfusion, and 10 through other routes. Over $40 \%$ of the 1324 infections were acquired in Nigeria, $24 \%$ in Ghana, $17 \%$ in Ivory Coast, $8 \%$ in Sierra Leone, 5\% in the Gambia, and the remainder in other west African countries (table 1). The ratio of HIV-2 and HIV-1/ HIV-2 co-infections to HIV-1 varied by country of infection, with the Gambia $(11.7 \%-15.2 \%)$ and Ivory Coast $(7.2 \%-$ $9.8 \%)$ having a high proportion of HIV-2 infections, and Nigeria $(0.7 \%-1.0 \%)$ a low proportion.

Women infected with HIV-2 were older at diagnosis than those infected with HIV-1 ( 35 years (IQR 32-36 years) versus 30 years (IQR 26-34 years)). With the exception of country of infection, there were no other differences in the demographics and characteristics of those infected with HIV-l and HIV-2 (data not shown).

Probably infected through heterosexual intercourse within the United Kingdom by a heterosexual partner infected in west Africa

Of the 130 adults infected through heterosexual intercourse within the United Kingdom by a heterosexual partner infected in west Africa, $89(68 \%)$ were HIV-1 infected and three $(2 \%)$ were HIV-2 or HIV-1/HIV-2 infected. For 38 (29\%), HIV type was not reported (fig $1 \mathrm{~B}$ ).

Of the total (130), $114(88 \%)$ were women and 16 men, with median ages at diagnosis of 31 years (IQR 25-35 years) and 40 years (IQR 38-50 years), respectively. Twenty three women $(20 \%)$ were pregnant at diagnosis. Where reported (113), 55 (49\%) patients were black African, 46 (41\%) white, and the remainder of other ethnicities. Country of birth was reported for 69 (53\%) individuals: 32 (46\%) were born in the United Kingdom , 28 (41\%) in Africa and the remainder in other regions. Where the partner's probable west African country of infection was reported (126), 57 (45\%) partners were probably infected in Nigeria, $44(35 \%)$ in Ghana, and the remainder in other countries. Ninety two (71\%) individuals were diagnosed in London. 
Table 1 HIV diagnoses made in England, Wales, and Northern Ireland among adults probably infected in west Africa by probable country of infection and HIV type: 1985 to 2003

\begin{tabular}{|c|c|c|c|c|c|c|c|}
\hline \multirow[b]{2}{*}{$\begin{array}{l}\text { Probable country } \\
\text { of infection }\end{array}$} & \multicolumn{4}{|c|}{ Reported HIV type } & \multirow[b]{2}{*}{ Total } & \multicolumn{2}{|c|}{$\begin{array}{l}\text { Proportion of reported HIV infections } \\
\text { typed as either HIV-2 or HIV-1/HIV-2 }\end{array}$} \\
\hline & HIV-1 & $\begin{array}{l}\text { HIV-2 or } \\
\text { HIV-1/HIV-2 }\end{array}$ & Subtotal & $\begin{array}{l}\text { Type not } \\
\text { reported }\end{array}$ & & $\begin{array}{l}\text { Lower } \\
\text { estimateł } \\
\text { (\%) }\end{array}$ & $\begin{array}{l}\text { Higher } \\
\text { estimateł } \\
\text { (\%) }\end{array}$ \\
\hline Nigeria & 387 & 4 & 391 & 155 & 546 & 0.7 & 1.0 \\
\hline Ghana & 217 & 15 & 232 & 84 & 316 & 4.7 & 6.5 \\
\hline Sierra Leone & 78 & 2 & 80 & 22 & 102 & 2.0 & 2.5 \\
\hline Gambia & 39 & 7 & 46 & 14 & 60 & 11.7 & 15.2 \\
\hline \multicolumn{8}{|c|}{$\begin{array}{l}\text { Liberia, Togo, Guinea, } \\
\text { Guinea-Bissau, }\end{array}$} \\
\hline Senegal ${ }^{*}$ & 33 & 6 & 39 & 16 & 55 & 10.9 & 15.4 \\
\hline \multicolumn{8}{|l|}{$\begin{array}{l}\text { Benin, Burkina Faso, } \\
\text { Mali, Mauritania, }\end{array}$} \\
\hline knownt & 15 & 2 & 17 & 6 & 23 & 8.7 & 11.8 \\
\hline West Africa total & 917 & 52 & 969 & 355 & 1324 & 3.9 & 5.4 \\
\hline \multicolumn{8}{|c|}{$\begin{array}{l}\text { Reports received by end of March } 2004 \text {. } \\
\text { *Between } 5 \text { and } 15 \text { individuals were diagnosed and reported as infected in each of these countries and had an HIV type reported. } \\
\text { tFewer than } 5 \text { individuals were diagnosed and reported as infected in each of these countries and had a HIV type reported. } \\
\text { tHigher estimate is the proportion of patients reported with a HIV type (subtotal) who were HIV-2 or HIV-1/HIV-2; lower estimate is the proportion of all reported } \\
\text { patients (total) who were HIV-2 or HIV-1/HIV-2. }\end{array}$} \\
\hline
\end{tabular}

\section{DISCUSSION}

Diagnoses of HIV infections probably acquired in west Africa have increased in E,W\&NI in recent years. HIV-1 infection predominates, with the number of HIV-2 diagnoses remaining low and the diagnosis rate relatively constant over time. The number of diagnoses of infections acquired through heterosexual intercourse within the United Kingdom by a heterosexual partner probably infected in west Africa have also increased in recent years, but remain relatively low. Again, HIV-1 infection predominates.

Just over half of those infected in west Africa and diagnosed in E,W\&NI were women, of whom nearly a third were pregnant at diagnosis. The majority were infected through heterosexual intercourse; were black African; and were born in Africa, mainly west Africa. By contrast, of those infected heterosexually in the United Kingdom by a heterosexual partner infected in west Africa, over 90\% were women, of whom a fifth were pregnant at diagnosis. Half were black African and 40\% African born.

Broadly, the proportion of HIV diagnoses in E,W\&NI associated with different west African countries reflects their population size, HIV prevalence, and the size of the respective population resident in the United Kingdom. Over $40 \%$ of those infected in west Africa were probably infected in Nigeria, which has a population of over 135 million and HIV prevalence of $5.4 \% .^{2}{ }^{13}$ In 2001 , there were over 86000 people born in Nigeria residing in E\&W, representing over $40 \%$ of all residents born in west and central Africa. ${ }^{14}$

The proportion of HIV-2 diagnoses also differed by west African countries of infection. Upper estimates indicate that $15 \%$ of those infected in the Gambia and diagnosed in E,W\&NI were HIV-2 positive, as were $10 \%$ of people infected in Ivory Coast and 7\% of those infected in Ghana. While $40 \%$ of those infected in west Africa were probably infected in Nigeria, only $1 \%$ of these individuals were HIV-2 positive. HIV-2 infected women were older than HIV-1 infected women, which may reflect the longer asymptomatic period of HIV-2 infection; older age at infection, or at least diagnosis, with HIV-2; or possible differences in patterns of migration between HIV-1 and HIV-2 infected women.

Miscategorisation of probable country of infection may have occurred by allocating the country of highest prevalence as the likely country of infection. The number of infections acquired within the United Kingdom from a partner infected in west Africa may therefore be underestimated, particularly among those resident in the United Kingdom but originating from west Africa. In addition, the number of men who have sex with men infected in west Africa may be underestimated, as country of infection is followed up only for heterosexuals when missing. Data on country of birth were only available for those reported on clinician HIV reports since $2000(<50 \%)$ and although probably known, HIV type was not reported for over a quarter of individuals. It is unclear whether data incompleteness caused any biases in results. Previous research suggests that HIV-2 diagnoses are not underreported within E,W\&NI (CDSC, unpublished), and the assumption that those without HIV type reported are likely to be HIV-l infected guides the lower estimate of the proportions given in the results table.

Within the context of the overall HIV epidemic in E,W\&NI, numbers of HIV diagnoses associated with west Africa are modest compared to those of infections associated with eastern Africa and more recently with south eastern Africa. ${ }^{1}{ }^{15}$ There have been 4809 infections probably acquired in east Africa diagnosed in E,W\&NI between 1985 and 2003 and a further 188 individuals diagnosed who were probably infected through heterosexual intercourse within the United Kingdom by a partner who was heterosexually infected in east Africa (CDSC, unpublished). Equivalent figures for south east Africa are 5779 and 217, respectively (CDSC, unpublished). In terms of HIV-2, the United Kingdom has experienced a lower prevalence of HIV-2 infection compared to some other European countries, for example Portugal and France. ${ }^{16}$ Prevalence of HIV-2 infection among STI clinic attendees in the United Kingdom was $0.006 \%$ (6/104 006) in 2002, as measured by the Unlinked Anonymous Prevalence Monitoring Programme. ${ }^{17}$

In conclusion, the number of people infected with HIV in west Africa and diagnosed in E,W\&NI has increased in recent years, and there has also been an increase in HIV infections acquired through heterosexual intercourse within the United Kingdom from a partner infected in west Africa. Health promotion specialists and west African communities in E,W\&NI need to be alerted to these increases so that appropriate measures can be taken to prevent further transmission. While the number of HIV-2 diagnoses remain relatively low and constant over time clinicians should be aware that for some west African countries the proportion of 
HIV-2 diagnoses is high, which has implications for HIV diagnostics and treatment: there are currently no commercial assays available for HIV-2 RNA quantification and conflicting evidence about whether HIV-2 viral loads are useful in clinical management ${ }^{7-9}$; those infected with HIV-2 are naturally resistant to non-nucleoside reverse transcriptase inhibitors (NNRTIs); HIV-2 infected pregnant women may not need to be given antiretroviral therapy and a caesarean section' ${ }^{10}$; and there are difficulties in diagnosing and monitoring HIV infection among children born to HIV-2 infected mothers.

\section{ETHICS}

Reports of new diagnoses and of those diagnosed and living with HIV are voluntary and confidential. To maintain patient confidentiality no names are held on the database and soundex codes are used instead. ${ }^{18}$ The reporting system has approval under the section 60 regulations of the Health and Social Care Act (Statutory Instrument 1438, June 2002). All data are stored on restricted and secure databases at CDSC, with strict adherence to the Data Protection Act and Caldicott Guidelines. ${ }^{19}$

\section{ACKNOWLEDGEMENTS}

We gratefully acknowledge the contribution of the many people who report to, and support, the national HIV surveillance systems. We would also like to thank Mike Taylor (Office for National Statistics), Rhian Tyler (Office for National Statistics), Dr Phillip Mortimer (SRMD), Dr Barry Evans (CDSC), Dr John Parry (SRMD), Dr Kevin Fenton (CDSC) and Dr Linda Lazarus (Department of Health).

\section{CONTRIBUTORS}

SD undertook the main writing of the paper and the analyses; all authors were involved in data collection, interpretation of the results, and drafting of the paper.

\section{Authors' affiliations}

S Dougan, B Patel, K Sinka, Department of HIV and Sexually Transmitted Infections, Communicable Disease Surveillance Centre, Health Protection Agency Centre for Infections, 61 Colindale Avenue, London NW9 5EQ, UK

J H Tosswill, Sexually Transmitted and Bloodborne Virus Laboratory, Specialist and Reference Microbiology Division, Health Protection Agency Centre for Infections, 61 Colindale Avenue, London NW9 5EQ, UK

\section{REFERENCES}

1 Health Protection Agency, SCIEH, ISD, National Public Health Service for Wales, CDSC Northern Ireland and the UASSG. Renewing the focus. HIV and other sexually transmitted infections in the United Kingdom in 2002. London: Health Protection Agency, November, 2003.

2 UNAIDS. 2004 Report on the global HIV/AIDS epidemic: 4th global report Geneva: Joint United Nations Programme on HIV/AIDS (UNAIDS) and World Health Organization (WHO), July, 2004.

3 Office for National Statistics. International migration, estimates from the International Passenger survey: migration from/to West Africa, 1978-2002 in 5 year groups.

4 Office for National Statistics. International Passenger Survey, 1998- 2002.

5 Health Protection Agency, CDSC. HIV infections and AIDS in the United Kingdom: monthly report - May 2003 (HIV-2 and HIV infections acquired through sex between men updated). Communicable Disease Report 2003;13(22).

6 Poulsen AG, Aaby P, Larsen O, et al. Nine-year HIV-2-associated mortality in an urban community in Bissau, West Africa. Lancet 1997;349:911-14.

7 Smith NA, Shaw T, Berry N, et al. Antiretroviral therapy for HIV-2 infected patients. J Infect 2001;42:126-33.

8 Mullins C, Eisen G, Popper S, et al. Highly active antiretroviral therapy and viral response in HIV type 2 infection. Clin Infect Dis 2004;38:1771-9.

9 Lyall H, Blott M, de Ruiter A, et al. Guidelines for the management of HIV infection in pregnant women and the prevention of mother-to-child transmission. HIV Medicine $2001 ; 2: 314-34$.

10 Smith NA, Kennedy J, Bewley S, et al. HIV-2 in pregnancy: to treat or not to treat? Int J STD AIDS 1998;9:246.

11 PHLS Communicable Disease Surveillance Centre, ICH (London), SCIEH. HIV \& AIDS in the UK. An epidemiological review: 2000. London, 2001.

12 Parry JV, Mortimer PP, Perry KR, et al. Towards error-free HIV diagnosis: guidelines on laboratory practice. Commun Dis Public Health 2003;6:334-50.

13 World Bank. World development indicators database, World Bank, September 2004 (www.worldbank.org/data/databytopic/POP.pdf).

14 Office for National Statistics. Census 2001. Table S015: country of birth by sex and age, England and Wales, (www.statistics.gov.uk/StatBase) Expodata/Spreadsheets/D7547.xls).

15 Sinka K, Mortimer J, Evans B, et al. Impact of the HIV epidemic in sub-Saharan Africa on the pattern of HIV in the UK. AIDS 2003;17: 1683-90.

16 Cazein F, Hamers F, Alix J, et al. Prevalence of HIV-2 infection in Europe. Eurosurveillance. 1996;3: 21-23, (www.eurosurveillance.org/em/v01 n03/ v0ln03.pdf)

17 Health Protection Agency, Institute of Child Health London, Scottish Centre for Infection and Environmental Health. Supplementary data tables of the Unlinked Anonymous Prevalence Monitoring Programme: data to the end of 2002.

18 Mortimer JY, Salathiel JA. 'Soundex' codes of surnames provide confidentiality and accuracy in a national HIV database. Commun Dis Rep 1995; 15:R183-6.

19 PHLS Communicable Disease Surveillance Centre. Quarterly Communicable Disease Review October to December 2001: Caldicott, Confidentiality and the Patient Information Advisory Group. J Public Health Med 2002;24:138-44. 